\title{
Improved Information on Heart Examination Results Uses a 12-lead Discrete Electrocardiograph
}

\author{
Sabar Setiawidayat
}

\begin{abstract}
The results of examination of the condition of the heart using an electrocardiograph are generally presented in an ecg paper. Using ecg paper because in the paper there are boxes that are used as guidelines for calculating wave amplitude and wave duration. If the required amplitude is information on peak amplitude and wave morphology information, then the duration is information on the value of segment duration, interval duration, and heart rate. As is known in the ECG paper the results of the examination that only some information is presented, so information that does not yet exist must be calculated manually using existing boxes. This manual calculation requires time and accuracy, so that this waiting time can cause the patient's disease stage to increase, and on the other hand that the lack of accuracy of the calculation can cause misdiagnosis. This study aims to provide information on clinical standard cardiac examination results using Electrocardiograph discrete (ECGd) and standard Electrocardiograph (ECGs). In ECGd, the leads of the heart signal are sampled at a frequency of $250 \mathrm{~Hz}$ so that it becomes discrete data. Maximum filtering on $1.6 \mathrm{mV}$ treshold data discrete peak $R$ is obtained in each cycle. The PQRST algorithm method is used to get the PQST peak and duration parameters. The results showed that the percentage of the amount of information from the ECGd examination was $82.4 \%$ while the results of the ECGs examination were $25.4 \%$
\end{abstract}

Index Terms-Information, cycle duration, peak amplitudo, data discrete, ECG.

\section{INTRODUCTION}

The heart organ can beat due to contractions and relaxation of the muscles of the left atrium, right atrium and left ventricle, right ventricle. The contraction is caused by the depolarisation of Atrium and Ventricle muscle cells because it is passed by impulses [1]. Figure 1 shows the anatomy of the heart organ while Figure 2 shows the cardiac conduction system.

Impulses are triggered autonomously, periodically and naturally by nerve cells called Pacemaker [2]. In Pacemaker there are three impulse triggers namely SA node (sino atrial node) which has a frequency of $60-100 \mathrm{bpm}$ (beat per minute), AV node (atrio ventricular node) which has a frequency of 40-60 bpm, and Purkinje fiber which has a frequency of 20- $40 \mathrm{bpm}$ [1]. The frequency is influenced by the sympathetic nerves originating in the spinal cord (spinal cord) and parasimpatic originating from the advanced marrow (medulla oblongata) [1].

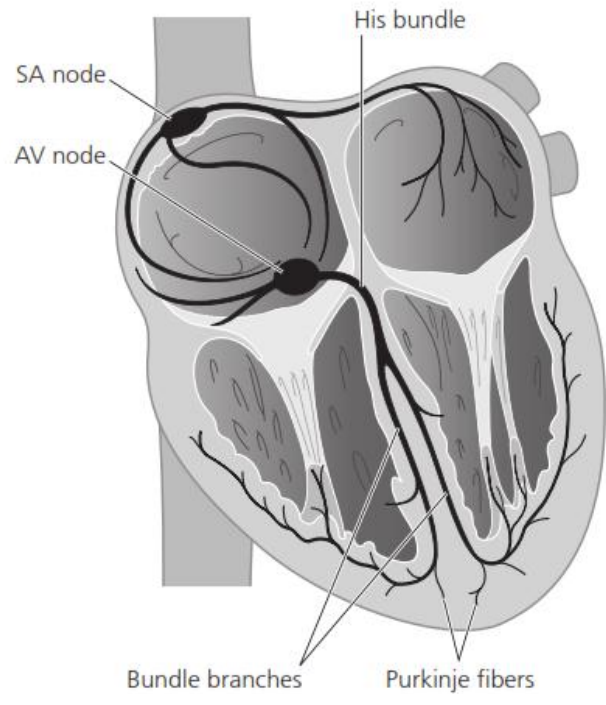

Fig 1. Structure and blood flow in the heart

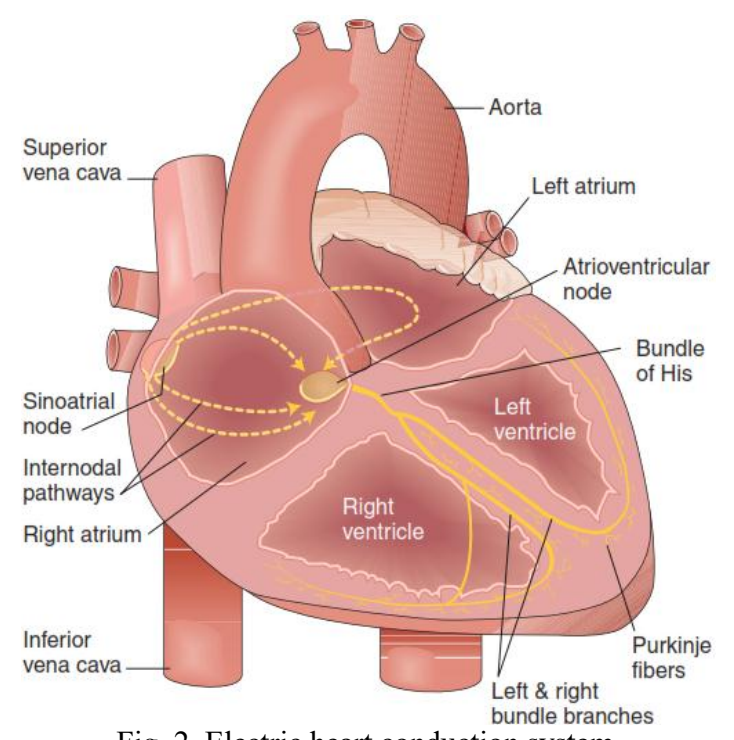

Fig. 2. Electric heart conduction system

Under normal circumstances, an impulse spark originating from the SA node works to cause an action potential (depolarization and repolarization), but if the SA node experiences a dysfunction it will be replaced by the AV node, as well as if the AV node is dysfunctional it will be replaced by Purkinje fiber [4]. The course of impulses in 1 period starting from the SA node to the Purkinje fiber is shown in Figure 3. 


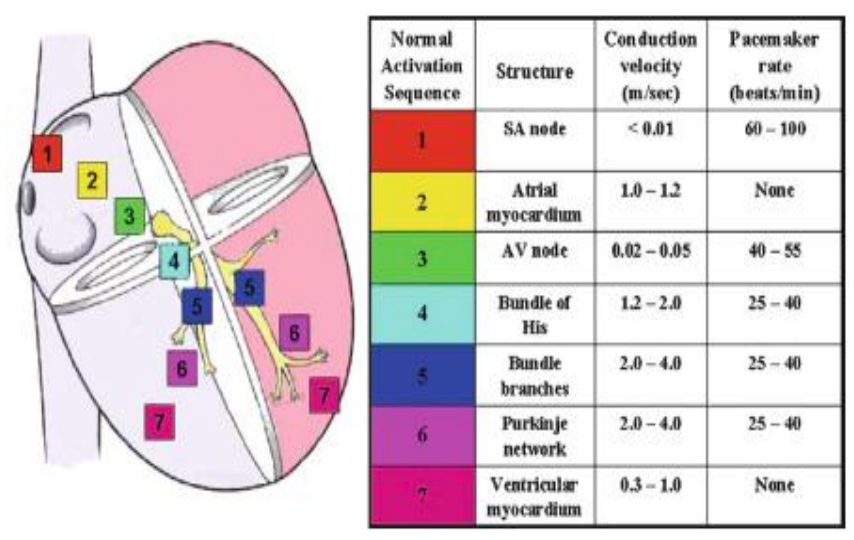

Fig. 3. The course of impulses in 1 period

The impulse trip as shown in figure 3 will generate a potential difference wave $(\mathrm{mV})$ as a function of time $(\mathrm{ms})$, ie a continuous analog signal [5]. This periodic impulse spark from Pacemaker will cause cycles containing waves. Heart examination results using an electrocardiograph are generally presented in a monitor or ecg paper, as shown in Figure 4.

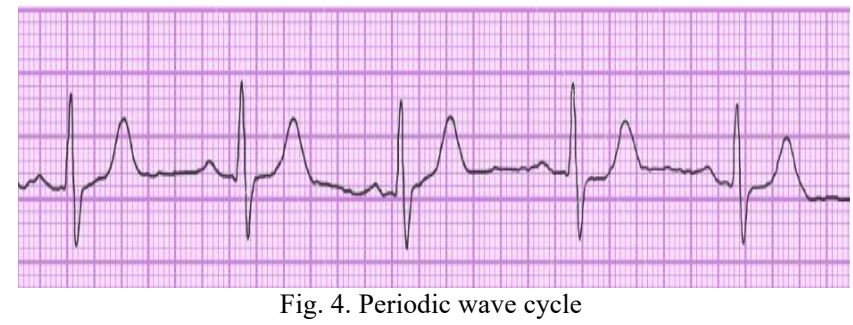

It appears in Figure 4 that there are 5 forms of periodic wave morphology, this is said to also have 5 cycles. The background of the small boxes on the ecg paper is a tool to calculate the value of the amplitude and duration value [6]. The boxes are $1 \mathrm{mV}$ for the vertical axis and $40 \mathrm{~ms}$ for the horizontal axis as shown in Figure 5.

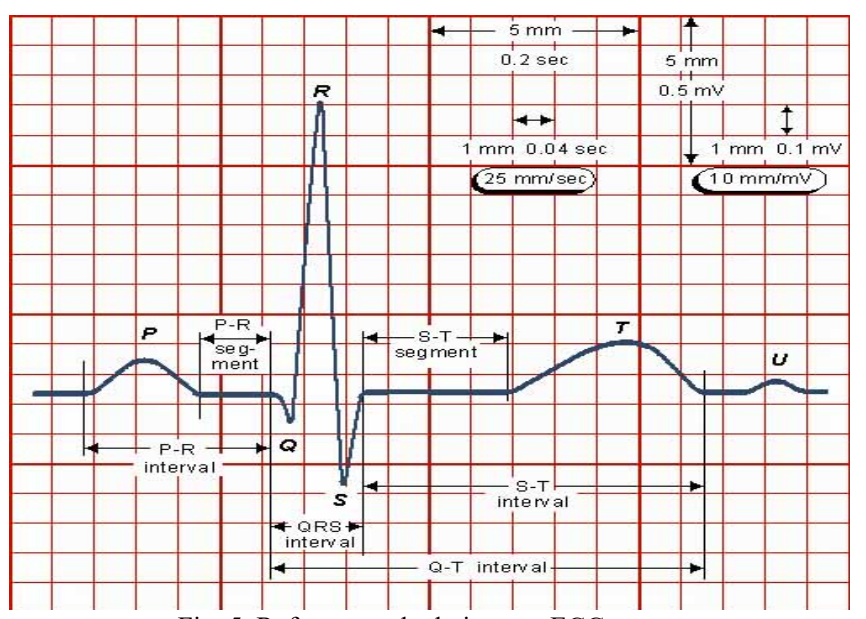

Fig. 5. Reference calculations on ECG paper

It appears in Figure 5 that there are waves $(\mathrm{P}, \mathrm{Q}, \mathrm{R}, \mathrm{S}$ and $\mathrm{T})$ and 2 segment duration (P-R and $\mathrm{S}-\mathrm{T}$ ) and 4 interval intervals (P-R, QRS, S-T and Q-T). Einthoven, 1903 [7] named the $\mathrm{P}$ wave for depolarization in the Atrium, the QRS wave for Ventricular depolarization and the $\mathrm{T}$ wave for Ventricular repolarization.
Segment is the duration between the end of the wave and the beginning of the next wave while the interval is the duration between the beginning of the wave until the beginning of the next wave.

P wave: Positive deflection due to atrial depolarization. QRS wave: is ventricular depolarization, is a systole ventricle, normal width $0.06-0.10$ seconds and consists of: 1) Q wave which is the first negative deflection, is interventricle septum depolarization activated from left to right, normal duration (except leads III and aVR ) less than 0.04 seconds ( 1 small square) and the height is less than one third the height of the $\mathrm{R}$ wave at the relevant tapping. 2) $\mathrm{R}$ Wave The $\mathrm{R}$ wave is the first positive deflection. 3) $\mathrm{S}$ wave: is the first negative deflection after $R$. T wave: is deflection due to ventricular repolarization. The PR segment: is formed from the end of the $\mathrm{P}$ wave to the beginning of the QRS complex and is a determinant of the isoelectric line. ST segment: is an early sign of left and right ventricular repolarization. The meeting point between the end of the ORS complex and the beginning of the ST segment is called the $J$ point. If the point is below the isoelectric line is called depression $\mathrm{J}$ point and if above the isoelectric line is called elevation $J$ point

PR interval: the time between the beginning of the $\mathrm{P}$ wave and the beginning of the QRS complex. The duration indicates the time of the depolarization wave propagation from the atrium to the ventricle. QRS interval: ventricle depolarization time, measured from the beginning of the $\mathrm{Q}$ wave (or R if $\mathrm{Q}$ is absent) to the end of the $\mathrm{S}$ wave. ST interval: measured from the end of the QRS complex to the end of the T wave. QT interval: is the total ventricle activity (from depolarization to ventricle repolarization). Measured from the start of the QRS complex to the end of the T wave. Normal duration depends on age, sex and heart rate. Average less than 0.38 seconds.

In clinical standard cardiac examination, 12 leads (leads) are used to see 6 parts from the vertical side (frontal, extremity) and 6 parts from the horizontal side (precordial, chest) as shown in Figure 6 [1].

\begin{tabular}{|c|c|c|c|}
\hline I Lateral & aVR & V1 Septal & V4 Anterior \\
\hline II Inferior & aVL Lateral & V2 Septal & V5 Lateral \\
\hline III Inferior & aVF Inferior & V3 Anterior & V6 Lateral \\
\hline
\end{tabular}
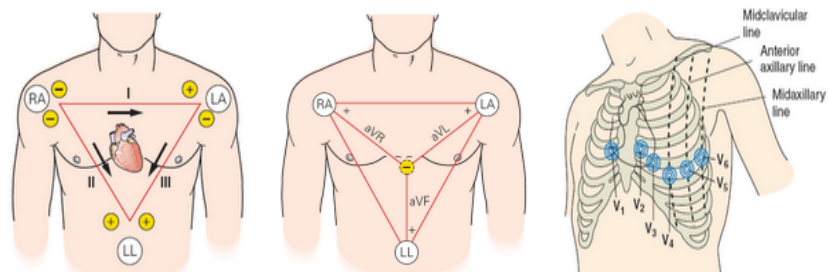

Fig. 6. ECG leads that conform to the cardiac side examination

The lead names in the Frontal section are lead I, lead II, lead III, aVR lead, aVL lead and aVF lead while Precordial section is lead V1, lead V2, lead V3, lead V4, lead V4, lead V5 and lead V6 [6]. The part of the heart that corresponds to the leads and placement of leads on the surface of the skin of the body is shown in figure 7 . 


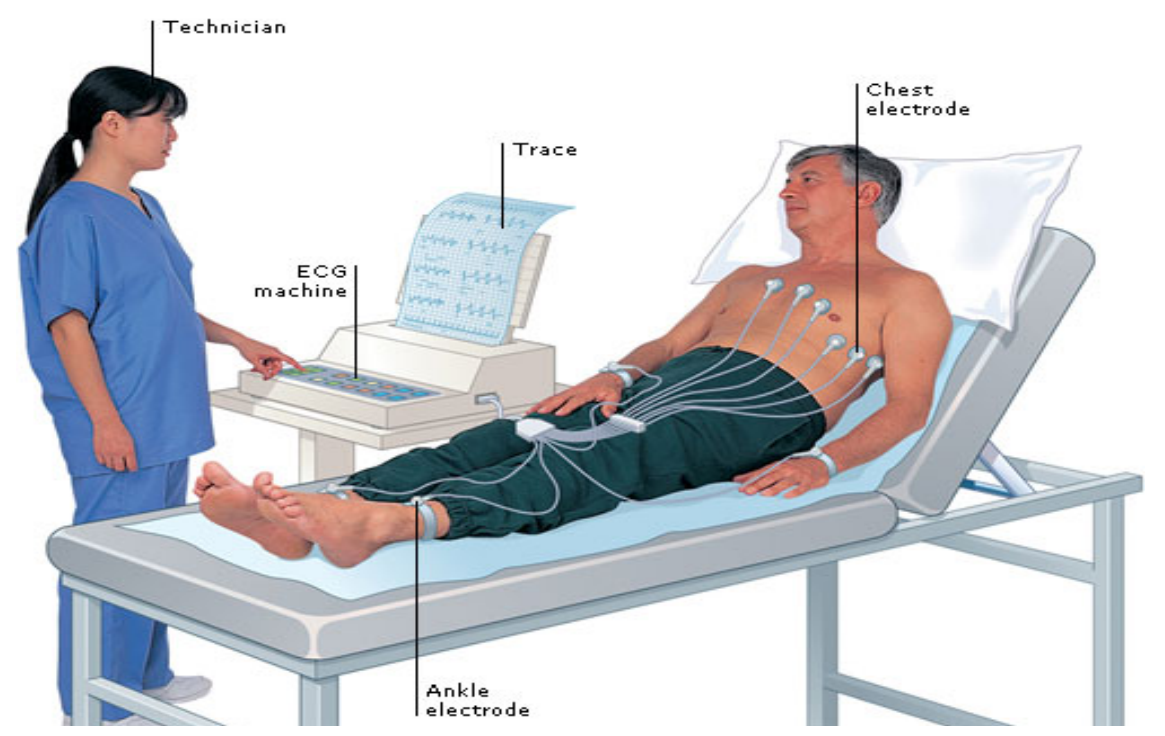

Fig. 7. The location of the placement of 10 electrodes on the surface of the body

Heart examination results are presented on the monitor screen or on ECG paper in the form of cardiogram waves and some numerical data information [8]. Data numbers in question are the value of the peak wave amplitude, the value of the duration of the segment, the duration of the interval, heart rate. Figure 8 shows the results of clinical standard examination (12 leads) on the ECG paper.

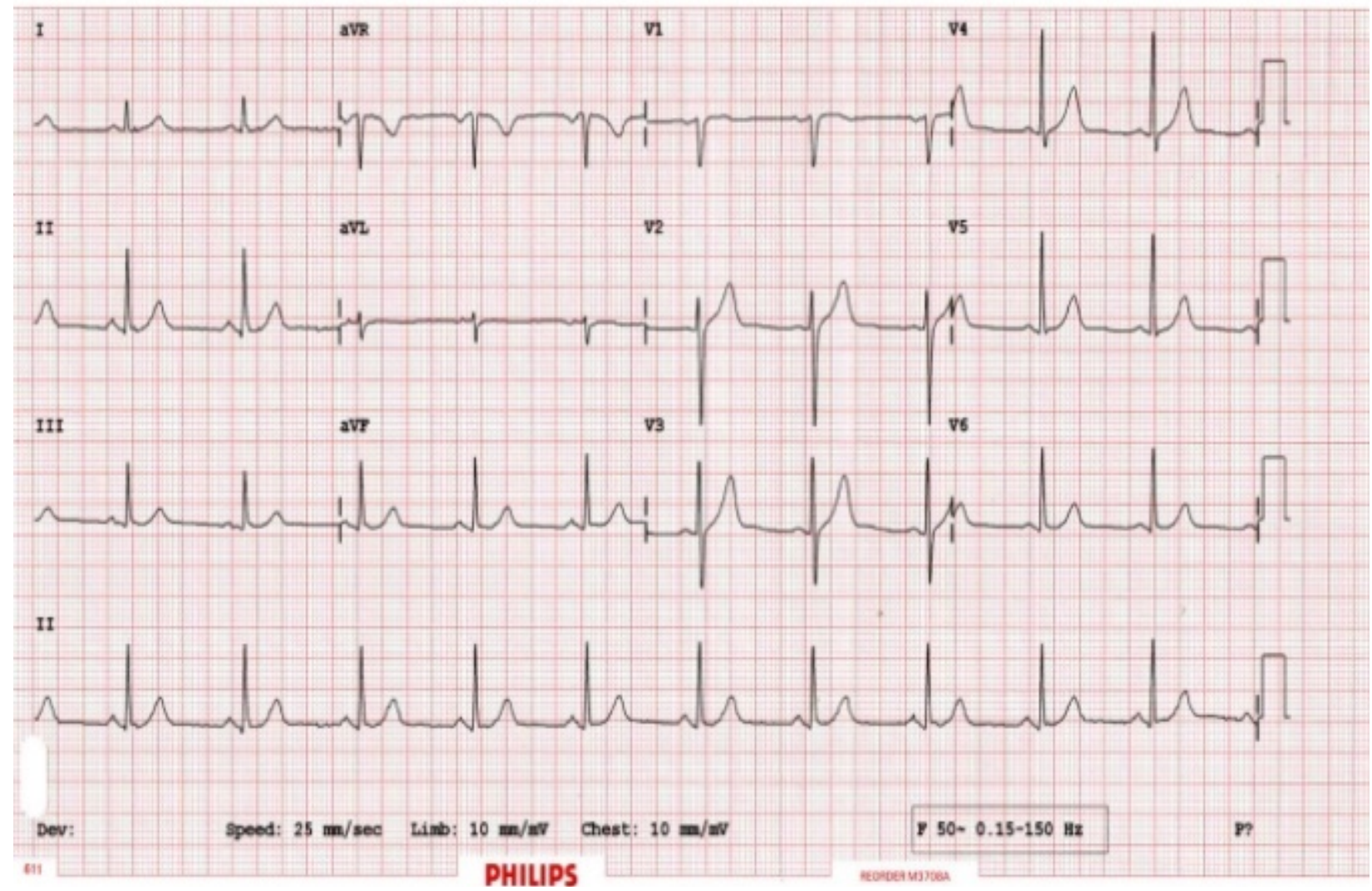

Fig. 8. 12-Lead ECG examination results

Based on the results of the examination as shown in Figure 8, the doctor or examiner will observe the morphology of the cardiogram and examine the peak Amplitude, segments and intervals needed by referring to Figure 5. Observation and manual calculations are carried out to interpret whether the PQRST waveform values, segments or the interval is still within normal or abnormal limits. The calculation is done because of the limited number of data information from the results of the examination, so the doctor or examiner uses reference boxes as shown in Figure 5 or using a ruler. Problems arising from this limited information are: 
1. Manual observation requires time to do the calculation, so the patient still has to wait for the results of the diagnosis. Heart disease is a progressive disease [9], which can be interpreted if medical treatment is not immediately carried out then the stage will increase, allowing the loss of life of the patient.

2. The calculation results are less accurate because they are calculated using a ruler or boxes that have a width limit (40 ms). Inaccuracies in calculations will result in errors in diagnosis

Some observers who have examined the peak R and PQRST amplitude of ECG waves include [10] filtering the difference in sound of 512 sample points at a sampling frequency of $1 \mathrm{kHz}$ using a high-order statistical algorithm. The maximum original signal and the minimum original signal from the ECG signal are transformed using FFT to observe the sound frequency. After the R-peak is detected, calculate the mean Square error (MSE) and the peak Signal Noise Ratio (PSNR). [11] propose a threshold variable of the signal that has been sampled $2 x f i$ in windowing. The maximum value of the data value above the threshold is the peak value R. [12] proposes a method of mathematical relationship between the highest value (peak and valley) of the ECG waveform and time. The proposed method is to design a GUI interface using Matlab using a simple mathematical algorithm. This program is not intended for clinical diagnosis but for scientific research purposes. [13] proposed an image processing method to convert samples at desired intervals, so that the MIT-BIH database could be used widely and universally. The MIT-BIH database for normal sinus rhythm is sampled at a frequency of $128 \mathrm{~Hz}$ and data is available at uniform intervals of $7.8125 \mathrm{~ms}$. The use of this data for analytical purposes with various techniques such as Artificial Neural Networks, correlation techniques etc., is required to have samples at the desired intervals. [14] determine the peak $\mathrm{R}$ by removing the sound from the data signal from the Physionet. Signals that have been free extracted from peak $\mathrm{R}$ and amplitude $\mathrm{mV}$ locations use Discrete Wavelet transforms. Use the algorithm implemented in Matlab R2012a. The threshold used is $0.5 \mathrm{mV}$. [15] states that conventional analysis through visual observation of ECG signals by doctors is ineffective and time-consuming. An automatic system is needed which involves the analysis of integrated digital signals. Propose software to capture images from ECG machines using a digital webcam camera. The project uses Matlab math software and image processing toolbox. The captured images are analyzed before sending via the internet. Software can extract information from ECG images or video based files. [16] synchronized the acquisition of Cardiovascular Magnetic Resonance (CMR) images with the heart rate using order statistics 4. Through certain threshold values, a peak $\mathrm{R}$ value was obtained. [17] proposed applying Discretization with the Continuous Wavelet Transform (CWT) method used for Bionic Wavelet Transform (BWT). The data used is the MIT-BIH Arrhythmia database. [12] investigated that the PQRST peak in an electrocardiogram signal could be detected based on the mathematical relationship between the highest value (peak and valley) of the ECG wave and time. [11] states that the value of $\mathrm{R}$ and QRS complexes on ECG waves can be correctly and efficiently detected using variable threshold. [18] suggested that the combination of the Discrete Wavelet Transform algorithm and the Pan-Tompkins method would be able to extract the QRS complex, P peak and T peak. [19] suggested three stages of determining the peak $\mathrm{R}$, namely the filter stage (sorting), the threshold stage and the comparison stage of the $\mathrm{R}$ value in the RR interval. [20] states that Matlab can measure waves, segments and ECG signal intervals using the Pan-Tompkins algorithm. Noting some observers who have examined the PQRST, it appears that ECG discrete data were obtained from image sampling (Ashis Birle, Hussain, Jitu, Lai Khin, Marcus), from the results of sound sampling (Ali Tariq, JS Dhir), and from MIT data BIH [21], [22], [23].

In this study, 30 patient samples were examined by clinical standards using Electrocardiograph Discrete (ECGd). ECGd is the design of researchers who have been tested in comparison with the results of the standard 12-lead Electrocardiograph (Fukuda Densi FX-121 and ESaote P80). The results of the 4 variable test in 30 patient samples using Kruskal-Wallis analysis showed that the examination results did not differ significantly at $\alpha=0.05$ [24].

\section{METHOD}

In this study, the data used are discrete data, that is, an analog signal from inspection results that have been sampled using 12-lead ECGd hardware [25]. The method used is the cycle determination method and the PQRST peak determination method as the conceptual framework shown in Figure 9 and Figure 10.

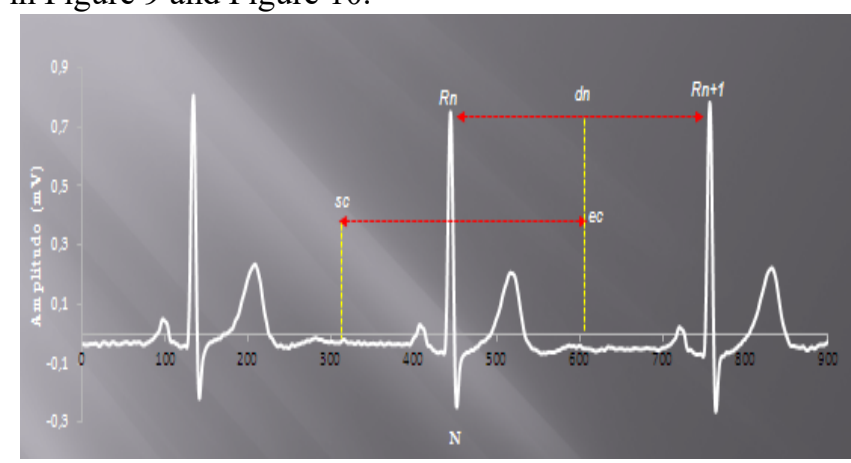

Fig. 9. The concept of determining the position and duration of the cycle

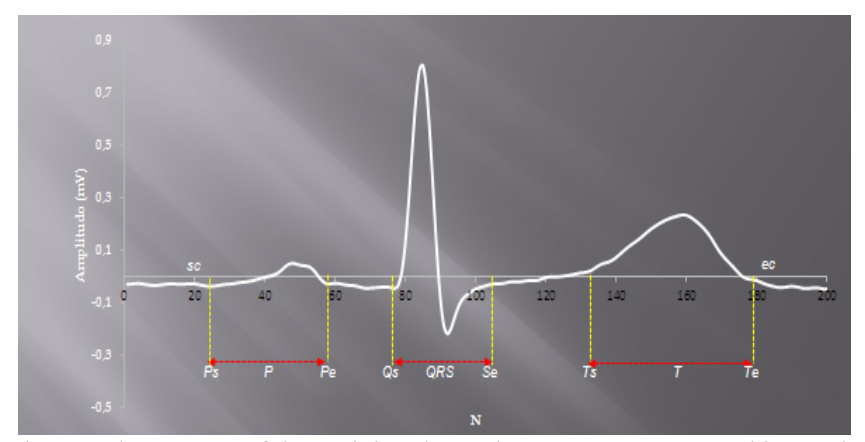

Fig. 10. The concept of determining the peak PQRST, segment and interval

Determination of peak $\mathrm{R}$ amplitude is based on the chosen potential different threshold value, for lead $\mathrm{I}$ is 0.6 while for lead II is 1.5 [26]. Obtained the peak value of R lead I in the nth sample position will also be obtained peak value $R$ for other leads in the nth sample position. The duration of peak $\mathrm{R}$ to the next peak $\mathrm{R}(\mathrm{RN}$ to $\mathrm{RN}+1)$ is used as the duration of the cycle by sliding backwards 0.5 times from the peak position of $\mathrm{RN}+1$.

If the beginning of the cycle is stated by the start cycle (sc) and the end of the cycle is stated as the end cycle (ec) then the position of the peak $\mathrm{Q}$ and the position of the peak $\mathrm{P}$ is 
the minimum value and the maximum value between sc to peak R. The position of the peak $\mathrm{S}$ and the position of the peak $\mathrm{T}$ is the minimum value and the maximum value between peak $\mathrm{R}$ to ec.

Based on the concepts in Figure 9 and Figure 10, a block diagram is designed to determine the peak amplitude and duration (segment, interval, HR) as in Figure 11.

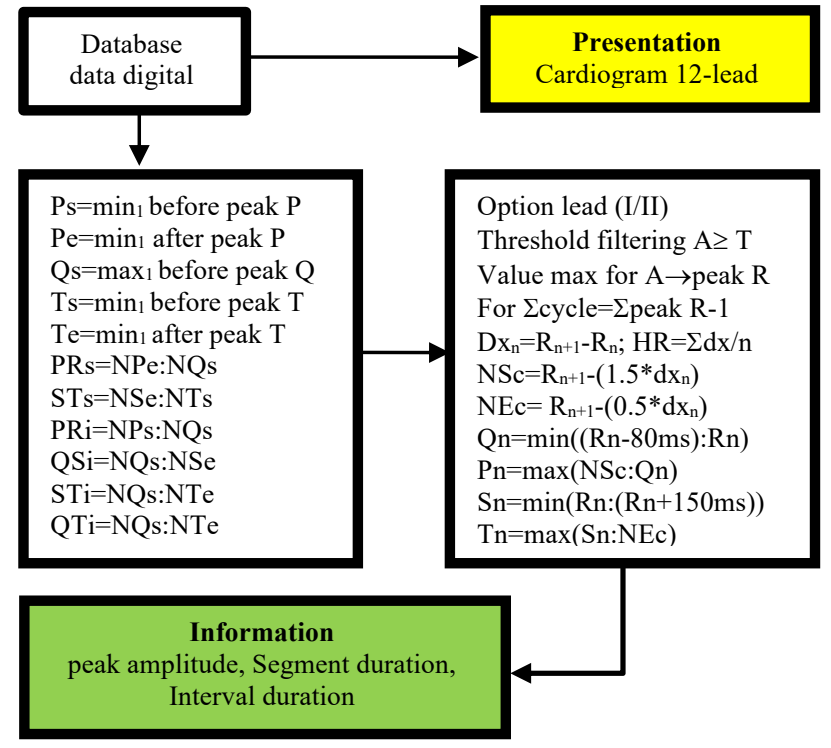

Fig. 11. The block diagram determines the amplitude and duration of the ECGd

A 12-lead cardiogram presentation is a presentation for the wave morphology of each lead, while information is a presentation of peak amplitude values, segment duration values, interval duration and heart rate. Leads that are used as reference waves are leads that consider that the $\mathrm{P}$ wave, QRS wave and T wave are clearly visible.

\section{RESULT}

Each patient was examined by clinical standard for 6 seconds using ECGs and ECGs installed in parallel. Patients are examined in a state of rest (relaxation) as a heart examination in general. The electrocardiograph device used is shown in Figure 12 and Figure 13, while the examination of the patient is shown in Figure 14.

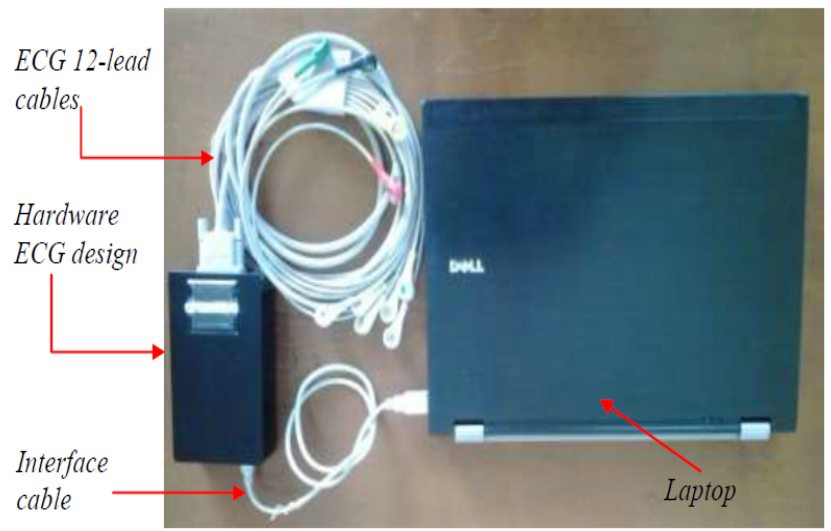

FIG. 12. ECGd inspection device

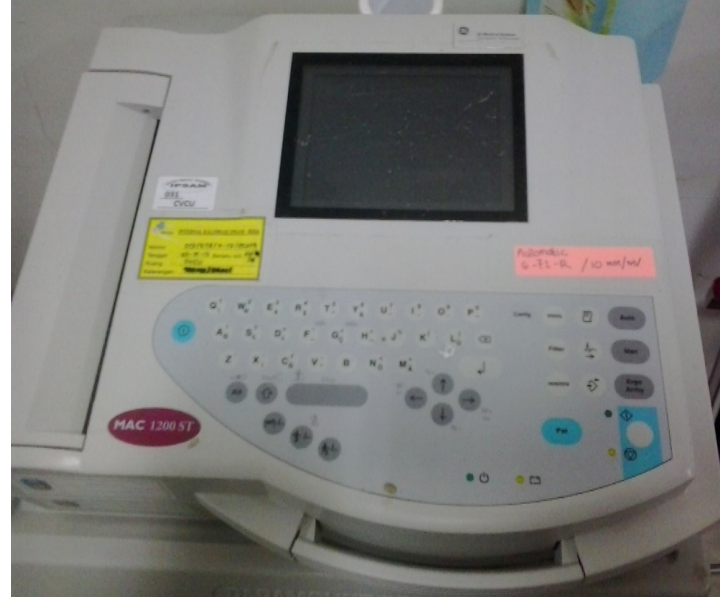

FIG. 13. ECGs checking device

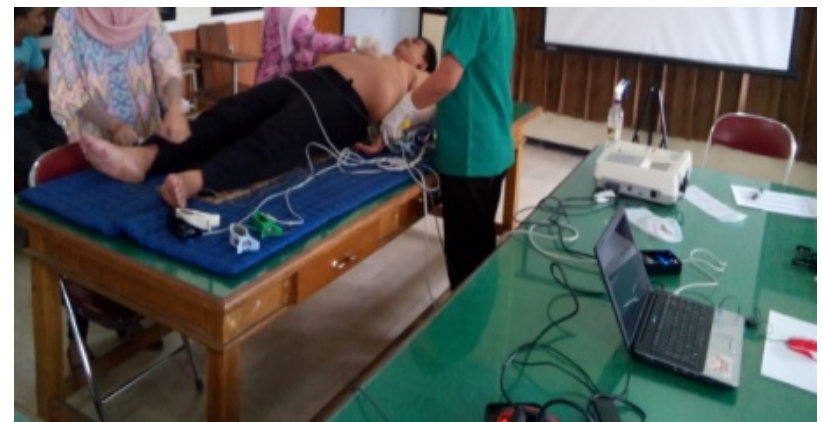

FIG. 14. During a patient's heart examination

The ECG cable output signal tapped from the body surface, is sampled with a $250 \mathrm{~Hz}$ sampling frequency so that it becomes discrete data, as shown in Figure 15.

\begin{tabular}{|c|c|c|c|c|c|c|c|c|c|c|c|}
\hline Hasad-2 & & & & & & & & & & & \\
\hline Fle Edv. Fon & Yien Hetp & & & & & & & & & & \\
\hline Save Samole & te: 256 & & & & & & & & & & \\
\hline & & -1826 & 2907 & -84 & -2823 & 41 & -1414 & -3228 & -2925 & 590 & \\
\hline-2110 & -3856 & -1746 & 2983 & -182 & -2801 & 58 & -1456 & -3266 & -2963 & 549 & 274 \\
\hline $\begin{array}{r}-2249 \\
\end{array}$ & -3948 & $\begin{array}{r}-1699 \\
-1699\end{array}$ & 3098 & -275 & -2824 & 56 & -1497 & -3293 & -2049 & 547 & 259 \\
\hline-2380 & -4047 & -1667 & 3213 & -357 & -2857 & 18 & -1566 & -3333 & -2927 & 568 & 249 \\
\hline-2458 & $-410 ?$ & -1649 & 3282 & -405 & -2878 & -35 & -1659 & -3387 & -2922 & 593 & 245 \\
\hline $\begin{array}{r}-2469 \\
\end{array}$ & -4136 & $\begin{array}{r}-1667 \\
-167\end{array}$ & 3302 & -401 & -2902 & -74 & $\begin{array}{l}-1753 \\
\end{array}$ & -3441 & -2934 & 618 & 249 \\
\hline-2446 & -4152 & -1736 & 3284 & -340 & -2944 & -91 & -1828 & $\begin{array}{l}-3487 \\
\end{array}$ & -22655 & 639 & 265 \\
\hline-2327 & -4192 & -1865 & 3259 & -231 & $\begin{array}{r}-24029 \\
-3029\end{array}$ & -84 & -1872 & -3527 & -3006 & 647 & 294 \\
\hline-2256 & -4252 & -1996 & 3254 & -130 & -3124 & -77 & -1904 & -3574 & $\begin{array}{r}-3061 \\
\end{array}$ & 634 & 328 \\
\hline-2259 & -4318 & -20199 & 3288 & -100 & -3189 & -99 & -1953 & -3650 & -3138 & 593 & 346 \\
\hline-2313 & $\begin{array}{l}-4351 \\
\end{array}$ & -2038 & 3132 & -138 & -3199 & -172 & -2042 & -3764 & -3235 & 532 & 330 \\
\hline $\begin{array}{l}-2335 \\
\end{array}$ & -4284 & -1949 & 3309 & -193 & $\begin{array}{l}-3117 \\
\end{array}$ & -272 & -2150 & -3886 & -3327 & 470 & 289 \\
\hline-2323 & -4149 & -1826 & 3236 & -249 & & -325 & -2217 & -3955 & -3362 & 435 & 242 \\
\hline $\begin{array}{l}-2363 \\
-\end{array}$ & -40.44 & -1681 & 3203 & -341 & $\begin{array}{l}-28630 \\
\end{array}$ & & & -3951 & -3328 & 433 & 201 \\
\hline-2501 & $\begin{array}{r}-4068 \\
\end{array}$ & -1567 & 3284 & $\begin{array}{l}-341 \\
-467\end{array}$ & -2818 & -228 & -2214 & -3913 & -3254 & 451 & 167 \\
\hline-2693 & -4236 & -1543 & 3464 & -575 & -2890 & -161 & -2218 & -3890 & -3185 & 480 & 145 \\
\hline $\begin{array}{l}-2851 \\
-2881\end{array}$ & -4466 & $\begin{array}{l}-1585 \\
-\end{array}$ & 3673 & -648 & -3026 & -133 & -2220 & -3897 & -3148 & $\begin{array}{l}518 \\
518\end{array}$ & 155 \\
\hline-3055 & $\begin{array}{r}-4409 \\
-4693\end{array}$ & -1638 & 3874 & $\begin{array}{l}-840 \\
-709\end{array}$ & -3166 & -129 & -2283 & -3915 & -3137 & 562 & 202 \\
\hline $\begin{array}{l}-3187 \\
-3187\end{array}$ & -4852 & $\begin{array}{r}-1665 \\
\end{array}$ & 4019 & -761 & -3259 & -135 & -2313 & -3934 & -3163 & 591 & 267 \\
\hline-3224 & -4920 & -1696 & 4072 & -764 & -3308 & -150 & -2345 & -3973 & -3239 & 569 & 307 \\
\hline-3136 & -4905 & -1769 & 4020 & -684 & -3337 & -196 & -2399 & -4046 & -3362 & 482 & 288 \\
\hline-2964 & -4822 & -1858 & 3893 & -553 & -3340 & -283 & -2478 & -4147 & -3506 & 351 & 212 \\
\hline-2817 & -4718 & -1901 & 3767 & -458 & -3310 & -368 & -2546 & -4231 & -3600 & 246 & 121 \\
\hline-2751 & -4625 & -1874 & 3688 & -439 & -3250 & -405 & -2578 & -4262 & -3601 & 235 & 69 \\
\hline-2730 & -4591 & -1861 & 3660 & -435 & -3226 & -392 & -2578 & -4253 & -3516 & 317 & 69 \\
\hline-2700 & -4652 & -1952 & 3676 & -374 & -3302 & -369 & -2581 & -4234 & -3404 & 433 & 93 \\
\hline-2676 & -4792 & -21116 & 3734 & -280 & -3454 & -378 & -2609 & -4230 & -3329 & 500 & 109 \\
\hline-2734 & -4990 & -2256 & 3862 & -239 & -3623 & -421 & -2653 & -4248 & -3323 & 507 & 104 \\
\hline-2873 & -5172 & -22299 & 4022 & -287 & -3736 & -481 & -2706 & -4286 & -3385 & 443 & 88 \\
\hline-3016 & -5258 & -2242 & 4137 & -387 & -3750 & -519 & -2738 & -4323 & -3457 & 386 & 88 \\
\hline 195 & -5251 & -2156 & 4173 & -470 & -3704 & -514 & -2731 & -4334 & -3481 & 393 & 117 \\
\hline-3113 & -5228 & -2115 & $\begin{array}{l}412 \\
4170\end{array}$ & $\begin{array}{r}-418 \\
-499\end{array}$ & $\begin{array}{r}-3672 \\
-3672\end{array}$ & -483 & -2696 & -4318 & $\begin{array}{l}-3401 \\
-3446\end{array}$ & $\begin{array}{l}323 \\
454\end{array}$ & 150 \\
\hline-3125 & -5283 & -2158 & 4204 & -484 & -3721 & -442 & -2647 & -4287 & -3379 & 519 & 158 \\
\hline $\begin{array}{l}-3169 \\
\end{array}$ & -5400 & -2231 & 4284 & -469 & -3816 & -423 & -2626 & -4265 & -3335 & 543 & 143 \\
\hline $\begin{array}{l}-13229 \\
-3228\end{array}$ & -5510 & -2282 & $\begin{array}{r}468 \\
4369\end{array}$ & $\begin{array}{l}-4092 \\
-473\end{array}$ & $\begin{array}{l}-38090 \\
-3996\end{array}$ & $\begin{array}{l}-423 \\
-456\end{array}$ & -2664 & -4281 & $\begin{array}{l}-33519 \\
-3359\end{array}$ & 504 & 117 \\
\hline-3225 & -5539 & -2314 & 4382 & -456 & -3927 & -547 & -2758 & -4337 & -3451 & 418 & 88 \\
\hline-3112 & $-544 ?$ & -2335 & 4279 & -389 & -3891 & -665 & -2863 & -4407 & -3566 & 325 & 66 \\
\hline-2942 & $\begin{array}{r}-52844 \\
\end{array}$ & -2344 & 4113 & -300 & -3813 & -751 & $\begin{aligned}-2919 & \end{aligned}$ & -4451 & -3636 & 273 & 62 \\
\hline-2828 & -5121 & -2293 & 3974 & -268 & -3707 & -775 & -2916 & -4454 & -3633 & 289 & 88 \\
\hline $\begin{array}{l}-2857 \\
\end{array}$ & -50036 & -2179 & 3946 & -339 & -3608 & -749 & -2877 & -4431 & -3570 & 361 & 132 \\
\hline-3005 & -5071 & -2066 & $\begin{array}{l}3408 \\
4038\end{array}$ & -470 & -3569 & -722 & -2846 & -4413 & -3500 & 442 & 161 \\
\hline-3141 & -5175 & -2034 & 4158 & -554 & -3605 & -739 & -28 & -4429 & -3475 & 475 & 142 \\
\hline-31155 & -5263 & -2108 & $\begin{array}{l}41100 \\
4209\end{array}$ & -524 & -3686 & -788 & -28 & -4461 & -3492 & 45 & 88 \\
\hline $\begin{array}{l}-3076 \\
\end{array}$ & -5255 & -2179 & $\begin{array}{l}42495 \\
4165\end{array}$ & -449 & -3717 & -828 & -28 & -4467 & -35 & 420 & 52 \\
\hline-3054 & -5175 & -212 & 4111 & -467 & -36. & -821 & -28 & & -34 & 43 & 74 \\
\hline $\begin{array}{r}-3169 \\
-3169\end{array}$ & -5104 & -19355 & 4136 & -617 & $\begin{array}{l}-352 \\
-\end{array}$ & -777 & -28 & -4344 & -3420 & 48 & 137 \\
\hline-3328 & -5065 & -1737 & 4196 & -796 & -3401 & -747 & -28 & -4278 & -3370 & 53 & 193 \\
\hline-3383 & -5059 & -1676 & 4221 & -854 & -3368 & $\begin{array}{l}-767 \\
\end{array}$ & -28 & -4269 & -3364 & 543 & 205 \\
\hline-3289 & -5064 & -1775 & 4176 & -757 & $\begin{array}{r}-3420 \\
\end{array}$ & -830 & -2904 & -4322 & -3409 & 493 & 173 \\
\hline-3148 & -5087 & -1939 & 4117 & -605 & -3513 & -921 & -2977 & -4408 & -3477 & 414 & 127 \\
\hline
\end{tabular}

FIG. 15. Discrete data from cardiac examination results 
The data in Figure 15 is the result of recording in a text file (notepad) consisting of 12 columns, which from the left to right sequence are columns I, II, III, aVR, aVL, aVF, V1, V2, V3, V4, V5 and V6 The number of records per column for 6 seconds is 1500 records $(6 \times 250)$.

Inspection results in Figure 15 are processed using the PQRST algorithm (Figure 11). Figure 16 shows the results of determining the cycle and the value of the amplitude, segment and interval numbers with reference to lead I while Figure 17 shows a 12-lead cardiogram in the first cycle.

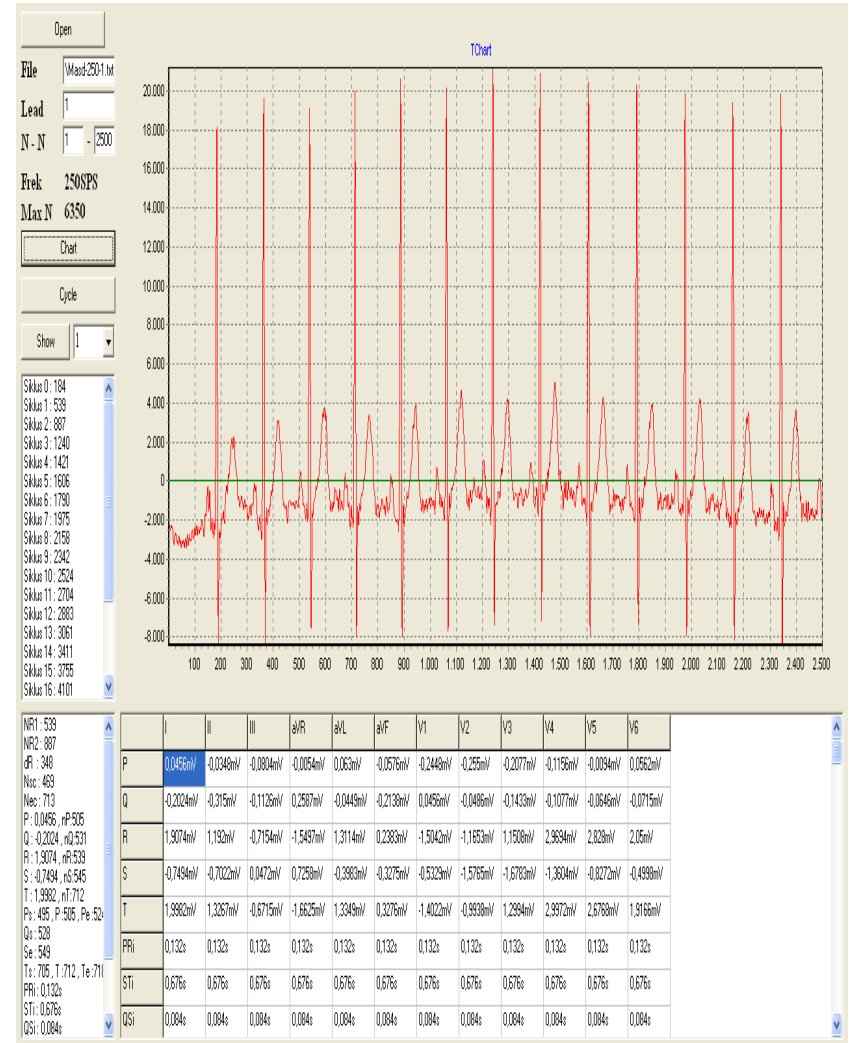

Fig. 16. Patient examination results for 6 seconds with fs $250 \mathrm{~Hz}$
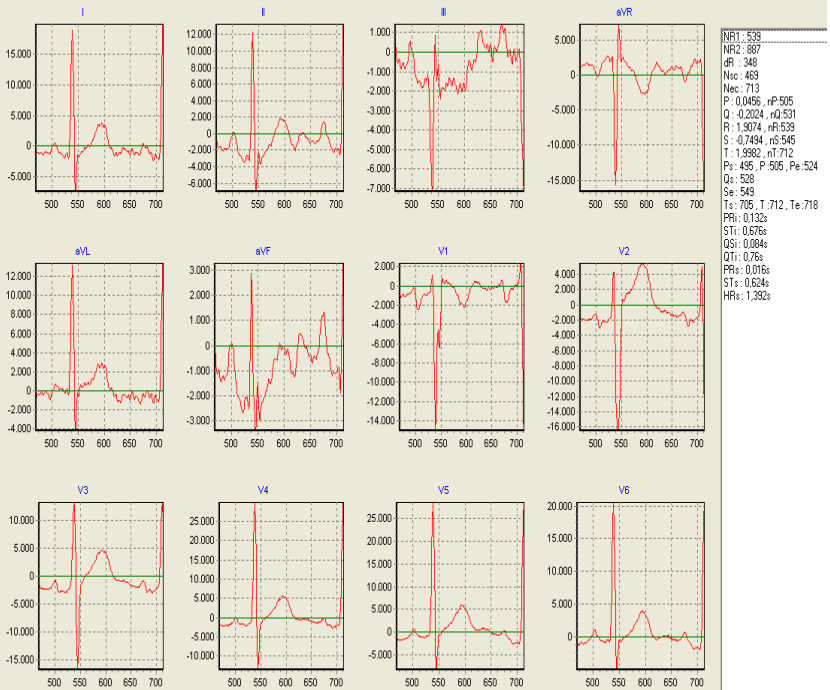

Fig. 17. 12-lead cardiogram in cycle 1

Results of clinical standard examinations using ECGs are shown in Figure 18 and examinations using ECGd devices in Figure 19.

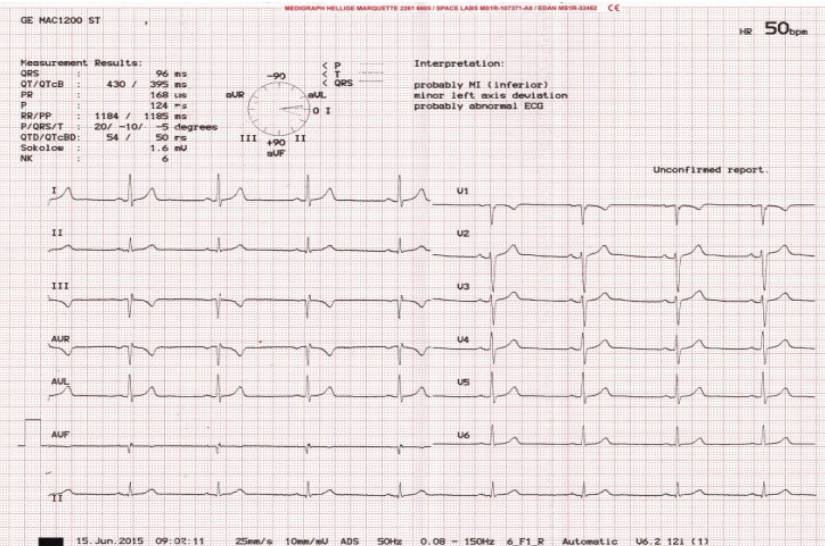

Fig. 18. Examination results use ECGs

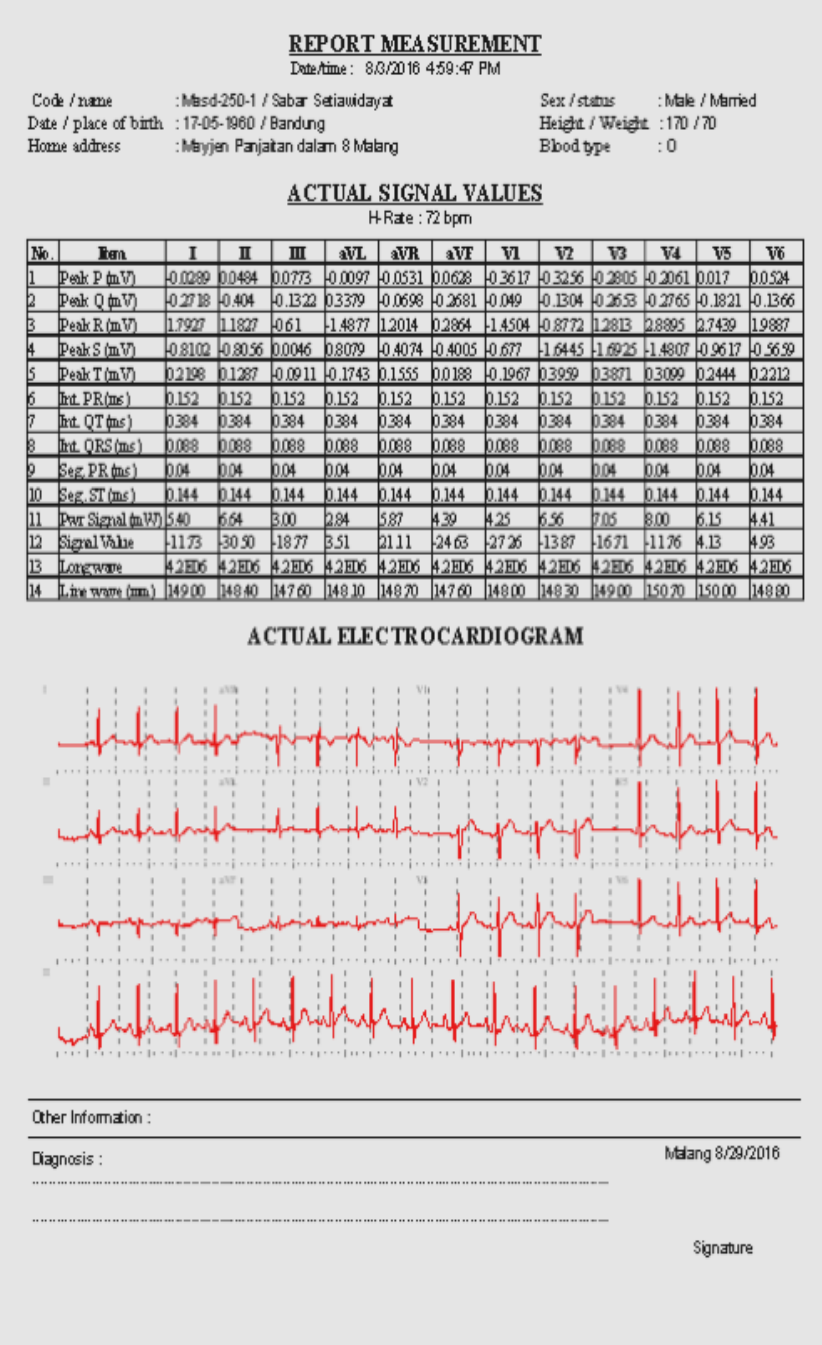

Fig. 19. The results of the examination using ECGd

It appears in Figure 18 that the information presented on ECG paper is 52 information, while in Figure 19 presented on plain paper is 168 information.

For the purposes of diagnosis, an information table of 204 boxes has been created. If there is information, the box is filled with an "*" sign.

Cardiogram information and numerical values of ECGd examination results in figure 19 are shown in table 1, while the results of ECGs examination in figure 18 are shown in table 2 . 
Table 1. Information on ECGd examination results

\begin{tabular}{|c|c|c|c|c|c|c|c|c|c|c|c|c|}
\hline Info & I & II & III & aVR & aVL & aVF & $\mathrm{V} 1$ & V2 & V3 & $\mathrm{V4}$ & V5 & V6 \\
\hline ECG & * & $*$ & $*$ & * & * & * & $*$ & $*$ & $*$ & * & $*$ & * \\
\hline Peak P & * & $*$ & $*$ & $*$ & * & * & $*$ & $*$ & $*$ & * & $*$ & $*$ \\
\hline $\begin{array}{l}\text { Peak } \\
\text { Q }\end{array}$ & * & $*$ & $*$ & * & * & * & $*$ & $*$ & $*$ & $*$ & $*$ & $*$ \\
\hline Peak R & $*$ & $*$ & $*$ & $*$ & $*$ & $*$ & $*$ & $*$ & $*$ & $*$ & $*$ & $*$ \\
\hline Peak S & $*$ & $*$ & $*$ & $*$ & * & $*$ & $*$ & $*$ & $*$ & $*$ & $*$ & $*$ \\
\hline Peak T & $*$ & $*$ & $*$ & $*$ & $*$ & $*$ & $*$ & $*$ & $*$ & $*$ & $*$ & $*$ \\
\hline $\begin{array}{l}\text { PR } \\
\text { seg. }\end{array}$ & * & $*$ & $*$ & $*$ & * & * & $*$ & $*$ & $*$ & $*$ & $*$ & $*$ \\
\hline ST seg. & $*$ & $*$ & $*$ & $*$ & $*$ & $*$ & $*$ & $*$ & $*$ & $*$ & $*$ & $*$ \\
\hline PR int. & * & $*$ & $*$ & $*$ & * & * & $*$ & $*$ & $*$ & $*$ & $*$ & $*$ \\
\hline $\begin{array}{l}\text { QRS } \\
\text { int. }\end{array}$ & * & $*$ & $*$ & * & * & * & * & $*$ & $*$ & * & $*$ & $*$ \\
\hline ST int. & $*$ & $*$ & $*$ & $*$ & $*$ & $*$ & $*$ & $*$ & $*$ & $*$ & $*$ & $*$ \\
\hline $\begin{array}{l}\text { QT } \\
\text { int. }\end{array}$ & * & $*$ & $*$ & $*$ & * & * & $*$ & $*$ & $*$ & * & $*$ & $*$ \\
\hline H. rate & $*$ & $*$ & $*$ & $*$ & $*$ & * & * & $*$ & $*$ & $*$ & $*$ & $*$ \\
\hline \multicolumn{13}{|l|}{$P$ axis } \\
\hline \multicolumn{13}{|l|}{$\begin{array}{l}\text { QRS } \\
\text { axis }\end{array}$} \\
\hline$T$ axis & & & & & & & & & & & & \\
\hline
\end{tabular}

Table 2. Information on ECG examination results

\begin{tabular}{|c|c|c|c|c|c|c|c|c|c|c|c|c|}
\hline Info & I & II & III & aVR & aVL & aVF & V1 & V2 & V3 & V4 & V5 & V6 \\
\hline ECG & $*$ & $*$ & $*$ & $*$ & $*$ & $*$ & $*$ & $*$ & $*$ & $*$ & $*$ & $*$ \\
\hline \multicolumn{13}{|l|}{ Peak P } \\
\hline \multicolumn{13}{|l|}{$\begin{array}{c}\text { Peak } \\
\text { Q }\end{array}$} \\
\hline Peak R & & $*$ & & & & & & & & & $*$ & \\
\hline Peak S & & $*$ & & & & & $*$ & & & & & \\
\hline \multicolumn{13}{|l|}{ Peak T } \\
\hline \multicolumn{13}{|l|}{$\begin{array}{l}\text { PR } \\
\text { seg. }\end{array}$} \\
\hline \multicolumn{13}{|l|}{ ST seg. } \\
\hline PR int. & & $*$ & $*$ & $*$ & * & * & $*$ & $*$ & $*$ & * & $*$ & $*$ \\
\hline $\begin{array}{l}\text { QRS } \\
\text { int. }\end{array}$ & & $*$ & $*$ & $*$ & * & * & $*$ & * & $*$ & * & $*$ & $*$ \\
\hline \multicolumn{13}{|l|}{ ST int. } \\
\hline \multicolumn{13}{|l|}{$\begin{array}{l}\text { QT } \\
\text { int. }\end{array}$} \\
\hline H. rate & & $*$ & $*$ & $*$ & $*$ & * & $*$ & $*$ & $*$ & $*$ & $*$ & $*$ \\
\hline P axis & & $*$ & & & & & & & & & & \\
\hline $\begin{array}{l}\text { QRS } \\
\text { axis }\end{array}$ & & $*$ & & & & & & & & & & \\
\hline T axis & & $*$ & & & & & & & & & & \\
\hline
\end{tabular}

It appears in table 1 that the box filled with "*" for ECGd is 168 information while in table 2 it is filled in "*" for ECGs is 52 information. Based on the amount of information, the percentage of information provided by the ECGd tool is $168 / 204=82.4 \%$ while the information from the ECGs tool is $52 / 204=25.4 \%$

\section{CONCLUSION}

The conclusions that can be given in this study are:

1. The results of the 12-lead discrete Electrocardiograph examination (12-lead ECGd) have been able to provide cardiogram information and PQRST peak values quickly and accurately on each lead

2. Examination results with discrete ECG do not require manual calculation time, so patients can be served quickly

3. Discrete ECG examination results do not require ecg paper because the results of the examination are printed on plain paper

4. The percentage of results of examination with ECGd obtained information of $82.4 \%$ while for ECGs information obtained of $25.4 \%$

\section{ACKNOWLEDGMENT}

This article is part of a Research funded by the Director General of Research and Development of the Ministry of Research, Technology and Education (DPRM) for the Higher Education Excellence Research scheme (PTUPT) in 2019-2021

\section{REFERENCES}

[1] A. C. Guyton and J. E. Hall, Textbook of Medical Physiology, 11th ed. Mississippi: Elsevier Saundes, 2006.

[2] J. R. Cameron and J. G. Skofronick, Medical physics. Wiley, 1978.

[3] D. B. Foster, Twelve-Lead Electrocardiography, Second. London: Springer-Verlag London, 2007.

[4] P. A. Iaizzo, Handbook of Cardiac Anatomy, Physiology, and Devices, ANSI Z39.48-1984 (American National Standards Institute) Permanence of Paper for Printed Library Materials. Totowa, New Jersey 07512: (c) 2005 Humana Press Inc., 2005.

[5] R. H. John, The ECG in Practice, Fourth Edition. Notingham UK Churchill Livingstone An imprint of Elsevier Science Limited, 2003.

[6] B. Chia, Cninical Electrocardiography, Third Edition. New Jersey: World Scientific, 2000.

[7] kartika Bawa and P. Sabherwal, "R-Peak Detection by Modified Pan-Tompkins Algorithm | IJOART Editor - Academia.edu," 2014. [Online]. Available: https://www.academia.edu/8224161/RPeak Detection by Modified Pan-Tompkins_Algorithm. [Accessed: 06-Jun-2017].

[8] G. D. Clifford, F. Azuaje, and P. E. McSharry, Advanced Methods and Tools for ECG Data Analysis, First Edition. Boston, London: 2006 ARTECH HOUSE, INC. 685 Canton Street Norwood, MA $02062,2006$.

[9] A. Natale, A. Al-Ahmad, P. J. Wang, and J. DiMarco, Cardiac Electrophysiology. London: Springer London Dordrecht Heidelberg New York, 2011.

[10] A. Tariq Bhatti and J. H. Kim, "R-Peak detection in ECG signal compression for Heartbeat rate patients at $1 \mathrm{KHz}$ using High Order Statistic Algorithm," J. Multidiscip. Eng. Sci. Technol. JMEST, vol. Vol. 2, no. Issue 9, pp. 7 (2509-2515), Sep. 2015

[11] A. Birle, S. Malviya, and D. Mittal, "A Novel Technique of R Peak Detecti on for ECG Signal Analysis: Variable Threshold Method," Int. J. Adv. Res. Electron. Commun. Eng. IJARECE, vol. 4, no. 5, pp. 3 (1167-1169), May 2015.

[12] H. A. Jaber AL-Ziarjawey and I. Cankaya, "Heart Rate Monitoring and PQRST Detection Based on Graphical user Interface with Matlab," Int. J. Inf. Electron. Eng., vol. 5, No.4, p. 6, Jul. 2015.

[13] J. Sharma, V. Kumar, S. Ayub, and J. P. Saini, "Uniform Sampling of ECG Waveform of MIT-BIH Normal Sinus Rhythm Database at Desired Intervals," Int. J. Comput. Appl., vol. 50, No.15, pp. 4 (69), Jul. 2012.

[14] Er. J. S. Dhir and Er. N. K. Panag, "ECG Analysis and R Peak Detection Using Filters and Wavelet Transform," Int. J. Innov. Res. Comput. Commun. Eng. IJIRCCE, vol. 2, no. 2, pp. 8 (2883-2890), Feb. 2014.

[15] L. K. Wee, Y. K. Jiar, and E. Supriyanto, "Electrocardiogram Data Capturing System and Computerized Digitization using Image Processing Techniques," Int. J. Biol. Biomed. Eng., vol. 3, no. 3, pp. 8 (27-34), 2009

[16] M. Schmidt, J. W. Krug, A. Gierstorfer, and G. Rose, "A real-time QRS detector based on higher-order statistics for ECG gated cardiac MRI," Comput. Cardiol. 2014, pp. 3 (733-736), 2014.

[17] M. Talbi, A. Aouinet, L. Salhi, and A. Cherif, "New Method of RWave Detection by Continuous Wavelet Transform," Signal Process. Int. J. SPIJ, vol. 5, no. 4, pp. 9 (165-173), 2011.

[18] I. S. S. Rao, T. S. Rao, and P. H. S. T. Murthy, "QRS Detection of ECG - A Statistical Analysis," ICTACT J. Commun. Technol., vol. 06, no. 01, pp. 4 (1080-1083), Mar. 2015.

[19] D. Sadhukhan and M. Mitra, "R-peak detection algorithm for ECG using double difference and RR interval processing," Elsevier Procedia Technol., vol. 4, pp. 5 (873-877), 2012.

[20] S. singh and N. Gandhi.N, "Pattern analysis of different ECG signal using Pan-Tompkin's algorithm," Int. J. Comput. Sci. Eng. IJCSE, vol. 02, No. 07, pp. 4 (2502-2505), 2010.

[21] D. Sadhukhan and M. Mitra, "R-peak detection algorithm for ECG using double difference and RR interval processing," Procedia Technol. Elsevier Ltd Open Access, vol. 4, p. 5, 2012, doi: 10.1016/j.protcy.2012.05.143. 
[22] J. Sharma, V. Kumar, S. Ayub, and J. P. Saini, "Uniform Sampling of ECG Waveform of MIT-BIH Normal Sinus Rhythm Database at Desired Intervals," Int. J. Comput. Appl., vol. 50, no. 15, pp. 6-9, Jul. 2012, doi: 10.5120/7845-0912.

[23] M. Singh, B. Singh, and V. Banga, "Effect of ECG Sampling Frequency on Approximate Entropy based HRV," ResearchGate, Aug-2014. [Online]. Available: https://www.researchgate.net/publication/284466918_Effect of EC G_Sampling_Frequency_on_Approximate_Entropy_based_HRV. [Accessed: 07-Jun-2017].

[24] S. Setiawidayat and R. Joegijantoro, "Algorithm for the Representation of Parameter Values of Electrocardiogram," Telkomnika, vol. Vol.16, no.3, no. Medical Engineering, p. 8, Jun. 2018, doi: DOI: 10.12928/TELKOMNIKA.v16i3.6934.

[25] S. Setiawidayat, R. Indra, D. Sargowo, and S. P. Sakti, "Determining The ECG 1 Cycle wave Using Discrete Data," $J$ Theor. Appl. Inf. Technol., vol. 88, No.1, pp. 8 (107-114), Jun. 2016.

[26] B. Chia, Clinical Electrocardiography, Third Edition. Singapura: World Scientific Publishing Co. Re. Ltd.Singapura, 2000.

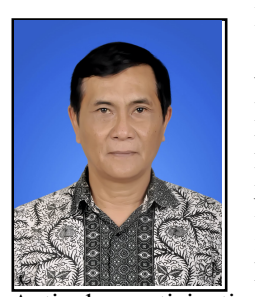

First A. Author Sabar Setiawidayat was born in 1960 in the city of Bandung, Indonesia. Completed undergraduate education in the Department of Electrical Engineering, Brawijaya University of Malang. In 1987 the Masters of Electrical Engineering was completed at the Institut Sepuluh Nopember, Surabaya in 2000. The doctoral education in medical engineering was completed at the Medical Faculty, Brawijaya University of Malang in 2017.

Actively participating in national seminars, international seminars and writing articles that have been published in proceedings and journals at national and international levels, which have been proven to have $\mathrm{h}$ index2. Since 2013 until now, it has always received research grants from the Ministry of Research and Technology, Higher Education, Indonesia 